\title{
A REFORMA DA UNIVERSIDADE DE COIMBRA E A NOVA ORDEM DOS ESTUDOS NA TRANSIÇÃO DO ANTIGO REGIME
}

\author{
MAGALHÃES, Justino Pereira de (Portugal, Lisboa) ${ }^{1 *}$ \\ 1 Universidade de Lisboa \\ https://orcid.org/0000-0001-9464-6782
}

\section{RESUMO}

Desde o final da Idade Média e particularmente com a revolução cultural e política do lluminismo, a questão da Universidade tornou-se também uma questão de Estado. A revolução científica e a revolução política que assinalaram a transição da primeira modernidade fizeram emergir um novo conceito de Universidade, vinculado ao lluminismo e ao Racionalismo como resposta àquela crise e como instância política. Dando curso à revolução científica e ajustando-se à modernização da administração pública, a Reforma Pombalina da Universidade de Coimbra insere-se numa corrente histórica de modernização fomentada e regulada pelo elemento estatal. Neste texto, será apresentada uma síntese que inclui aspectos sociopedagógicos da Reforma Pombalina e Mariana da Universidade de Coimbra que assinalaram a relação entre a Universidade e a sociedade portuguesa na transição do Antigo Regime. Far-se-á referência ao estatuto e à função da Universidade Reformada na Nova Ordem dos Estudos. Pela natureza sumária e exploratória deste texto, serão utilizadas fundamentalmente fontes secundárias.

PALAVRAS-CHAVE: Universidade. Reforma Pombalina da Universidade de Coimbra. Nova Ordem dos Estudos.

\section{THE REFORM OF THE UNIVERSITY OF COIMBRA AND THE NEW ORDER OF STUDIES IN THE TRANSITION OF THE OLD REGIME}

\begin{abstract}
Since the end of the Middle Ages and particularly the Enlightenment cultural and political revolution, the University question became also a State question. The scientific and political revolution that marked the first modernity transition identified a new concept of University, linked to the Enlightenment and the Rationalism as an answer to such crisis and political instance. Giving vent to the scientific revolution and adjusting to public administration modernization, the Coimbra University Pombal Reform is inserted in a
\end{abstract}

historical current of modernization fed and adjusted by the State element. In this context will be presented an overview that includes pedagogic and social aspects of University of Coimbra Pombal and Mariana Reform that marked the relation between the University and the Portuguese society in the Ancient Regime transition. The reference will be made to the reformed university statute and function in the New Studies State. By the summarized and exploratory nature of this text, secondary sources will be used essentially.

\section{KEYWORDS: University. Pombal Reform University of Coimbra. New Studies State.}

\section{LA REFORMA DE LA UNIVERSIDAD DE COIMBRA Y EL NUEVO ORDEN DE LOS ESTUDIOS EN LA TRANSICIÓN DEL ANTIGUO RÉGIMEN}

\section{RESUMEN}

Desde finales de la Edad Media y particularmente con la revolución cultural y política de la llustración, la cuestión de la Universidad se ha convertido en una cuestión de Estado. La revolución científica y la revolución política que señalaron la transición de la primera Modernidad hicieron emerger un nuevo concepto de Universidad vinculado a la llustración y al Racionalismo como respuesta a aquella crisis y como instancia política, cumpliendo objetivos en el marco del Estado-Nación en formación. La Reforma Pombalina de la Universidad de Coimbra se inserta en una corriente histórica de modernización fomentada y regulada por el elemento estatal. En este artículo se presenta una síntesis que incluye aspectos sociopedagógicos de la Reforma Pombalina y Mariana de la Universidad de Coimbra que marcaron la relación entre la Universidad y la sociedad portuguesa en la transición del Antiguo Régimen. Se hará referencia al estatuto y a la función de la Universidad Reformada en el Nuevo Orden de los Estudios. Por la naturaleza sumaria y exploratoria de este texto, se utilizarán fundamentalmente fuentes secundarias.

PALABRAS CLAVE: Universidad. Reforma Pombalina de la Universidad de Coimbra. Nueva Orden de los Estudios.

Educação \& Formação, Fortaleza, v. 4, n. 10, p. 7-17, jan./abr. 2019

DOI: https://doi.org/10.25053/redufor.v4i10.865

http://seer.uece.br/redufor

ISSN: 2448-3583 


\section{INTRODUÇÃO}

Desde o final da Idade Média e particularmente com a revolução cultural e política do lluminismo, a Universidade, como instituição científica e formativa, associou o nacional e o transversal. Destinada a sedimentar a racionalidade e a formar as elites, a Universidade era fonte de humanismo e de ciência e era a instituição nacional de legitimação do conhecimento. No decurso da modernidade, assegurou a norma e o transnacional. Com o lluminismo, a Universidade tornou-se também assunto de Estado. Uma constante na história das Universidades foi a tensão entre os Estados-Nações e a evolução científico-pedagógica, podendo admitir-se alguma sobreposição entre História das Universidades e Histórias da Universidade. Tal diversidade conviveu com a constante de natureza humanista e científica e com a normalização pedagógica.

Na génese e na mutação da Universidade moderna está uma epistemologia, cuja construção comporta a relação entre universalidade (in)formativa e formação específica, seja por ramo humanístico, científico ou técnico, seja por ramo do conhecimento. A dimensão pedagógica assegurava a articulação entre formação geral e formação específica e ajustava-se à mudança no método e no conceito de ciência. A Universidade reformada ficaria associada ao desenvolvimento como progresso e à estatização-nacionalização do ensino. Em Portugal, este longo processo veio a prolongar-se até a segunda metade do século XIX - Regeneração. Desde a Reforma Pombalina, no contexto das Luzes, que a História da Universidade ficou associada à História do Ensino.

\section{NOVOS ESTATUTOS E NOVAS FACULDADES}

A Reforma da Universidade de Coimbra contou com os pareceres da Junta de Providência Literária, criada por Carta Régia de 23 de dezembro de 1770. Cabia à Junta ponderar sobre o estado da Universidade e apontar "[...] os Cursos científicos e os métodos [...] para a fundação dos bons e depurados estudos das Artes e Ciências". Em resultado, a Junta apresentou ao Rei, em agosto de 1771, o Compêndio histórico do estado da Universidade de Coimbra, que veio a ser publicado em 1772. Data de 28 de agosto de 1772 a assinatura, pelo rei D. José I, da Carta de Roboração dos novos Estatutos da

Educação \& Formação, Fortaleza, v. 4, n. 10, p. 7-17, jan./abr. 2019 
Universidade, tendo sido então extinta a Mesa da Junta da Fazenda da Universidade e criada a Junta de Administração e Arrecadação (GOMES, 1977).

Por decretos de 1771, tinham sido aprovados os Mapas com os novos lentes da Universidade: Teologia - oito lentes e seis substitutos; Cânones - sete lentes e cinco substitutos; Leis - nove lentes e seis substitutos; Matemática - três lentes; Filosofia dois lentes. A cerimónia de fundação da nova Universidade teve lugar em Coimbra em 26 de setembro de 1772, com a presença do Marquês de Pombal. As aulas nas Faculdades de Teologia, Cânones, Leis e Medicina tiveram início em novembro desse ano. Em 1773, estava em curso a implantação do Museu de História Natural e estava a funcionar o Gabinete de Física Experimental, para onde tinham sido transportados os materiais didácticos existentes no Colégio dos Nobres, onde, entretanto, tinha sido encerrado o ensino das disciplinas científicas. Em 1774, estava a funcionar o Teatro Anatómico. Também em 1774, foi aprovada a criação da nova Faculdade das Artes.

\section{A UNIVERSIDADE REFORMADA E A ORDEM DOS ESTUDOS}

A concentração e a progressão dos Estudos em torno da Universidade Reformada ficaram assinaladas pela Provisão de 16 de outubro de 1772. Através dessa Provisão, foi restituído à Universidade o Colégio das Artes, para a educação da sociedade nobre e civil das três Províncias do Norte e Partido do Porto que pretendesse cursar as Humanidades. Em 1773, foram afixados editais naquelas três Províncias, informando sobre tal possibilidade, ainda que o Colégio das Artes não houvesse sido remodelado de imediato. A Universidade de Coimbra passou a interferir no fomento e na organização do ensino. Por Carta Régia de 17 de dezembro de 1794, foi abolida a Real Mesa da Comissão Geral sobre o Exame e a Censura dos Livros e criada a Junta da Directoria-Geral dos Estudos e Escolas destes Reinos, com exercício de funções na Universidade de Coimbra. Esta Junta era formada pelo reitor, que presidia, por seis deputados e por um secretário, todos membros do corpo académico. Desde 1791 que, nos termos do Alvará de 17 de janeiro desse ano, tinham sido transferidas para a Universidade de Coimbra a direcção e a inspecção dos Estudos Menores e aulas da Comarca e cidade de Coimbra.

Educação \& Formação, Fortaleza, v. 4, n. 10, p. 7-17, jan./abr. 2019 
Em 1801, a Direcção-Geral dos Estudos dirigiu a todos os mestres e professores, incluindo os particulares, um inquérito sobre a situação e funcionamento das escolas. A Reforma Pombalina e Mariana da Universidade congregou as componentes de ensino e formação para a constituição de uma elite que modernizasse o país nos planos científico, técnico e administrativo. A Reforma assegurou a integração e a continuidade curricular desde os Estudos Menores até a Universidade. Tal sequência foi assegurada, entre outros aspectos, pelo facto de as principais individualidades que participaram da Reforma da Universidade haverem assumido também a Reforma dos Estudos Menores nas respectivas Congregações. Correlativamente foi desenvolvido o ensino técnico e profissional. A investigação científica continuou, em boa parte, assegurada por Academias.

Os historiadores coincidem no relevo conferido pela Reforma Pombalina ao ensino científico. Foram criadas as Faculdades de Medicina, de Matemática e de Filosofia. A Faculdade de Filosofia incluía a Física Experimental, a Química e a História Natural. O ensino beneficiou-se com a introdução da componente experimental, como sistematizou Carvalho (1986, p. 466):

\begin{abstract}
Para todas as matérias em que tinham cabimento a observação e a experimentação, foram criados os meios necessários para poderem ser estudadas segundo os métodos então modernos, e tudo amplamente, com largueza de vistas, até nalguns casos com aparato espectacular. Assim foram criados, para a Medicina, o Hospital Escolar, o Teatro Anatómico e o Dispensário Farmacêutico; para a Matemática, o Observatório Astronómico; para a Filosofia, o Gabinete de História Natural, o Jardim Botânico, o Gabinete de Física Experimental [...] e o Laboratório Químico.
\end{abstract}

A Biblioteca da Universidade de Coimbra mereceu especial atenção por parte dos Reformadores. Na Carta Régia de 9 de outubro de 1777, enviada ao reitor da Universidade, nomeando o doutor António Ribeiro dos Santos para bibliotecário da livraria da Universidade, a rainha reconhecia:

[...] a necessidade que para fomentar e facilitar os progressos dos Estudos da mesma Universidade há de que se faça patente e Biblioteca dela; e que nela haja um Bibliotecário, que a dirija, e a cujo cargo esteja a boa Conservação, e Custódia dela. (MOTA, 1991, p. 200).

António Ribeiro dos Santos era professor da Universidade e, na Minuta para o Regimento da Livraria da Universidade de Coimbra, deixou informação sobre a situação da biblioteca e explicitou um princípio que assinala o valor do livro e da leitura no movimento que veio a ficar conhecido por llustração:

Educação \& Formação, Fortaleza, v. 4, n. 10, p. 7-17, jan./abr. 2019

DOI: https://doi.org/10.25053/redufor.v4i10.865

http://seer.uece.br/redufor 
A Livraria da Universidade para ser útil ao público e facilitar por seus grandes subsídios os progressos das Artes e das Ciências, deve estar abastadamente provida de livros e mais comodidades literárias; aberta e patente a todos; e servida por oficiais que residam nela. (SANTOS apud MOTA, 1991, p. 213).

Na sequência, refere-se à conveniência de haver abundância "[...] dos livros capitais de todas as Artes e Ciências e dos mais que se julgarem de muito uso e utilidade" (SANTOS apud MOTA, 1991, p. 213). Sugeria a edificação de dois gabinetes, um de Antiguidades com manuscritos e outro servindo de Museu, podendo conservar globos, cartas geográficas e instrumentos necessários às Artes. O bibliotecário deveria elaborar catálogos para o bom uso da biblioteca. Disporia de verba para actualização e aquisição de livros, devendo solicitar pareceres de eruditos professores das Faculdades e de Humanidades sobre livros úteis às faculdades e às profissões. Deveria também manter correspondência com mercadores de livros e bibliotecários, dentro e fora do Reino, colhendo notícias bibliográficas e literárias, que mandaria adquirir. Deveria encomendar bibliografias, jornais, efemérides, mercúrios, gazetas e outros "Livros de Novas Literárias" para conhecer o estado das Artes e Ciências entre as Nações "[...] e os vários Livros e obras que se vão compondo e descobrindo nelas" (SANTOS apud MOTA, 1991, p. 213).

Assim ficaram traçados o estatuto e o lugar da biblioteca para a investigação e a leitura por parte de académicos, estudantes e outros leitores, podendo ser franqueada a leitura de obras proibidas àqueles que apresentassem licença para tal. A Reforma da Universidade veio consagrar as diferentes dimensões da cultura letrada na ciência, na cultura e na constituição e mobilização da sociedade contemporânea.

\section{RELEVO DA COMPONENTE (IN)FORMATIVA}

A tónica da Reforma Pombalina da Universidade recaiu sobre o ensino - o ensino como informação, profissionalização, aç̧ão. Uma das principais inovações foi o ensino científico-técnico destinado a profissionais especializados, assim boticários, engenheiros, topógrafos, arquivistas. Esse ensino beneficiou os locais especializados, entretanto criados, nomeadamente o Dispensatório Farmacêutico ou Dispensário Farmacêutico, associados ao Hospital-Escolar. Em conformidade com os Estatutos de 1772 (apud PITA, 1991, p. 12), ficou estipulado que: 
[...] haja uma Botica, na qual se preparem os remédios que forem necessários aos enfermos. E sendo por outra parte muito conveniente que os Estudantes médicos se exercitem nas Operações de Farmácia, como lhes é encarregado por estes Estatutos; e que na mesma Botica se criem também Boticários de profissão com a inteligência necessária, para exercitarem a Arte de um modo saudável à vida dos meus Vassalos.

Os alunos do Ensino Farmacêutico candidatos a boticários deveriam cumprir dois anos de prática no Laboratório Químico e dois anos no Dispensatório Farmacêutico. Findos os quatro anos, deveriam ser examinados por um júri constituído pelo lente de Matéria Médica, por seu demonstrador e pelo boticário do Dispensatório, "[...] fazendo-lhes as perguntas necessárias, para mostrarem a sua inteligência: tirando por sorte três Operações Químicas e outras tantas Farmacêuticas para as executarem na presença de todos os sobreditos" (PORTUGAL, 1772 apud PITA, 1991, p. 13). Se obtivessem aprovação, passariam a exercer a profissão de boticários, caso contrário deveriam continuar o exercício da prática no Dispensatório.

Os alunos candidatos a boticários inscreviam-se como operários ou práticos no Laboratório Químico e no Dispensatório Farmacêutico, devendo escutar as lições proferidas pelo lente de Matéria Médica destinadas aos estudantes de Medicina. O ensino farmacêutico foi assim contemplado pela Reforma da Universidade como formação teórica e prática dos futuros médicos e como ensino prático para os boticários. Em 1794, Pina Manique criou uma Escola de Boticários na Casa Pia de Lisboa, em conformidade com o estipulado nos Estatutos da Universidade de Coimbra.

A Universidade de Coimbra passou a ser constituída por seis faculdades: Teologia, Cânones, Leis, Medicina, Matemática e Filosofia. Os candidatos à Universidade deveriam ter concluído os Estudos Menores. Como faltassem professores em algumas partes do Reino, nomeadamente em Grego e Filosofia, os estudantes poderiam inscrever-se na Universidade com essas matérias em atraso, devendo, entretanto, fazer prova delas. $O$ ingresso nalguns cursos exigia a frequência de Preparatórios, já na Universidade. Assim sucedia com os candidatos a Medicina, Teologia e Direito (Cânones e Leis), que deveriam frequentar algumas cadeiras nas Faculdades de Matemática e Filosofia. 


\section{REFORMA DA UNIVERSIDADE E ANTROPOLOGIA CULTURAL}

O desígnio fundamental das Luzes, tal como foi consignado por Kant, era o de ousar fazer uso do conhecimento. Tal desígnio saiu fortalecido com a associação entre a componente experimental e a capacidade de leitura - a leitura como conhecimento. Aprender através do livro, aprender lendo, interpretando, glosando, (re)criando. Uma das modalidades mais frequentes, para a conclusão dos estudos universitários, passou a ser a apresentação de uma tese. No ensino, as postilas (explicações dadas pelo professor) deram lugar às leituras comentadas. As bibliotecas de faculdade e as bibliotecas escolares tornaram-se elementos necessários e obrigatórios nas instituições de ensino. A ordem do conhecimento foi replicada na ordem dos livros e na sistemática das bibliotecas.

A componente curricular universitária, ou mais recentemente terciária, era formada pelos elementos científico, metodológico, didáctico e sociocultural. $\mathrm{Na}$ pedagogia universitária, a informação, a investigação e a aprendizagem foram estruturadas em método, sendo do método que fundamentalmente dependeu a organização curricular. Esta articulava a componente científica, a montante, com a formação sociocultural e profissional, a jusante. As componentes de especialização e de profissionalização patentes na organização didáctica não deixaram de ser, em boa parte, determinadas pela capacidade e pela formação prévia dos públicos, bem como pelas regras de acesso. Como matriz do conhecimento, instância credenciada e hegemónica no plano nacional, no decurso da modernidade, a Universidade abriu-se a novos públicos.

A história da Universidade moderna reflecte, com particular relevo, o complexo formado pelas componentes científica, política, pedagógica, social. Não obstante, algumas oscilações dependentes do modelo de Universidade e as (re)configurações daquele complexo tenderam a originar novos ciclos históricos. A história da Universidade é assinalada por transformações naquele núcleo duro, sendo a dimensão social frequentemente obscurecida por debates de natureza científica, política ou pedagógica. É possível distinguir dois modelos no desenvolvimento desse complexo: o modelo centralizado (in)formativo, de Universidade-Ensino, que foi cultivado na Reforma Pombalino-Mariana da Universidade de Coimbra e que, em boa parte, corresponde ao modelo napoleónico; e o modelo de Universidade-Investigação, tal como foi cultivado pelas universidades alemãs. Ao primeiro tem sido atribuída a designação de modelo

Educação \& Formação, Fortaleza, v. 4, n. 10, p. 7-17, jan./abr. 2019

DOI: https://doi.org/10.25053/redufor.v4i10.865

http://seer.uece.br/redufor 
napoleónico, pois que foi levado pelos franceses ao Império, enquanto o modelo alemão ficou associado a Wilhelm von Humboldt. Para o primeiro modelo, a investigação e a produção científica tinham lugar fora da universidade; formação e investigação constituíam modelos específicos. Por contraste, a universidade alemã assumiu a investigação como modalidade de formação e como prerrogativa do ensino de grau superior.

\section{UNIVERSIDADE E TRANSFORMAÇÃO SOCIOCULTURAL}

Ocupando o centro da relação entre ciência e sociedade, a Universidade mudou de forma lenta. Entre o século XVI e meados do século XVIII, havia em Portugal duas Universidades: a Universidade de Coimbra e a Universidade Teológica de Évora. Tomando como referência essas Universidades, observa-se que a decadência da Universidade do Antigo Regime coincidiu com a crise do jesuitismo e com a ruptura da latinidade. A revolução científica e a revolução política que caracterizam a transição da primeira modernidade fizeram emergir um novo conceito de Universidade, vinculado ao lluminismo e ao Racionalismo como resposta à crise e como instância política no quadro do Estado-Nação em formação. A Reforma Pombalina da Universidade de Coimbra culminou com a promulgação dos Estatutos em 1772. Foi um movimento de modernização inserido numa corrente histórica favorável ao fomento e à regulação por parte do elemento estatal. $\mathrm{Na}$ base do processo reformador esteve a publicação do Compêndio histórico do estado da Universidade de Coimbra, editado pela Junta da Providência Literária, criada em 1771. Escrito sob o teor e o formato de Parecer, associado à Dedução cronológica, aquele estudo foi erigido em velo acusatório da pedagogia e do conceito de Universidade Jesuítica.

Em 28 de agosto de 1772, D. José I assinou a Carta de Roboração dos novos Estatutos da Universidade de Coimbra, que foram traduzidos para latim ao mesmo tempo que eram elaborados. O latim mantinha, desse modo, o prestígio de língua erudita e de ciência, não obstante a controvérsia linguística que dividia os reformistas perante os novos conceitos e a nova realidade científica e institucional. A Reforma Pombalina introduziu a componente experimental, com imediata repercussão na Faculdade de Medicina, para a qual foram criados Laboratórios. Anexos à Universidade, funcionariam o Hospital Escolar, o Teatro Anatómico, o Dispensário Farmacêutico, o Museu de História Natural, o Gabinete

Educação \& Formação, Fortaleza, v. 4, n. 10, p. 7-17, jan./abr. 2019 
de Física Experimental, o Laboratório Químico, o Observatório Astronómico, o Jardim Botânico e a Imprensa da Universidade. Foram fundadas novas faculdades: a de Filosofia e a de Matemática. A pedagogia seria centrada na observação e na experimentação, devendo, para fazer face aos novos descobrimentos da ciência, os professores ser "mestres e inventores", em conformidade com a terminologia adoptada pelo reitor e membro da comissão de reforma, D. Francisco de Lemos.

Parte dos membros da Comissão de Reforma da Universidade tinha integrado a Comissão de Reforma dos Estudos Menores e Preparatórios. A Reforma da Universidade ficara associada à Nova Ordem dos Estudos, à evolução científica, à formação técnica e profissional. Assim, dando curso à formação de um letrado que conciliaria a formação de humanista com a de cientista, as disciplinas de Matemática e de Filosofia foram tornadas obrigatórias designadamente para os estudantes de Medicina. A Universidade de Coimbra foi reformada como Universidade do Estado, pelo que, na sua Relação com data de 1772, o reformador-reitor, D. Francisco de Lemos, contabilizou e projectou o total de alunos inscritos e diplomados por curso. Estabeleceu um juízo sobre a justa proporção entre o total de alunos por especialidade e as necessidades do país. Constatava o reitor que a afluência à Universidade tinha vindo a aumentar particularmente nos primeiros anos da Reforma, mas entendia que tal aumento ficou a dever-se ao facto de a Universidade ter passado a ser procurada por estudantes oriundos de estratos sociais ligados ao mundo do trabalho. De facto, a reforma tinha proporcionado uma maior amplitude ao ensino e uma maior correspondência entre os estudos e as necessidades da sociedade. Asseverava, todavia, o referido reitor que a profundidade e a exigência constituiriam um meio de regularizar a frequência.

A Reforma Pombalina da Universidade de Coimbra, integrada ao Racionalismo, compõe um ciclo de Reformas. Pelas décadas seguintes, os reformadores dividiam-se quanto ao lugar das Humanidades na Universidade Reformada e quanto à função da Universidade, pendendo uns para a componente científico-investigativa e outros para a componente formativo-técnica. De igual modo, também a determinação do estatuto da Universidade continuou mergulhada em controvérsia, mantendo-se o dilema entre prosseguir o modelo napoleónico instituidor de uma universidade estatal ou assumir uma universidade fundacional, centrada na investigação e articulada com a sociedade, como pretendiam os partidários do modelo propugnado por Wilhelm von Humboldt. 
Em 1794, havia sido criada a Junta da Directoria Geral dos Estudos e Escolas do Reino, integrada à Universidade de Coimbra. Desde então e até meados do século XIX, a Universidade Reformada ficou directamente envolvida na coordenação, normalização e articulação verticalizante da política educativa. Competia-lhe controlar e organizar 0 protossistema da instrução nos domínios público e particular. A integração vertical da estrutura ensinante, constituindo uma pirâmide que culminava na Universidade, era uma sistémica instrucional que compreendia também o Colégio das Artes.

Na Relação Geral do estado da Universidade, que redigira em 1777, contendo o resumo do processo de implementação da Reforma, o reitor Francisco de Lemos introduziu o conceito de "Educação Nacional", como devendo merecer aos soberanos a maior vigilância por ser o princípio e a origem da "Felicidade Pública das Monarquias" (ARAÚJO, 2014). Gomes (1977, p. 250) destacou como característica fundamental da Reforma Pombalina da Universidade de Coimbra "[...] a introdução, no ensino, da observação e da experimentação, de modo que os seus professores fossem, ao mesmo tempo, 'Mestres e inventores'”. Fortalecida na representação do Estado, de novo única e rejuvenescida com laboratórios e métodos que asseguravam a observação, a experimentação e a argumentação, a Universidade Reformada abria-se a novos perfis letrados e dava curso a uma nova ordem dos estudos. A atribuição da coordenação e da legitimação da ciência e do ensino (incluindo o da Teologia, já com D. João VI, em 1805) à Universidade Reformada acabaria por refazer, no contexto do Estado Moderno, a vocação original dos Estudos Gerais como legitimação e vértice da pirâmide cultural e educativa. Assim, pois, a inscrição da Universidade Reformada na Nova Ordem dos Estudos foi, no fundamental, a de haver sido erigida em cúpula do mundo letrado e assumir a superintendência do ensino.

\section{REFERÊNCIAS}

ARAÚJO, A. C. Dirigismo cultural e formação das elites no Pombalismo. In: ARAÚJO, A. C. (Coord.). O Marquês de Pombal e a universidade. 2. ed. Coimbra: Universidade de Coimbra, 2014. p. 15-48.

ARAÚJO, J. C. S. (Org.). A universidade iluminista (1798-1921): de Kant a Max Scheler. Brasília, DF: Liber, 2011.

Educação \& Formação, Fortaleza, v. 4, n. 10, p. 7-17, jan./abr. 2019 
CARVALHO, R. História do ensino em Portugal: desde a fundação da nacionalidade até o fim do regime de Salazar-Caetano. Lisboa: Calouste Gulbenkian, 1986.

GOMES, J. F. Dez estudos pedagógicos. Coimbra: Almedina, 1977.

MAGALHÃES, J. A Convenção de Bolonha e a Reforma do Ensino Universitário. In: ARAÚJO, J. C. S. (Org.). A universidade iluminista (1929-2009): de Alfred Whitehead a Bologna. Brasília, DF: Liber, 2011. p. 251-263.

MAGALHÃES, J. Da cadeira ao banco: escola e modernização (séculos XVIII-XX). Lisboa: Educa, 2010.

MOTA, L. C. M. A. A "Minuta para o Regimento da Livraria da Universidade de Coimbra" de António Ribeiro dos Santos. Algumas notas para o seu enquadramento históricocultural. In: COMISSÃO ORGANIZADORA DO CONGRESSO "HISTÓRIA DA UNIVERSIDADE", 7., 1991, Coimbra. Actas do Congresso História da Universidade. Coimbra: Universidade de Coimbra, 1991. p. 197-228.

PITA, J. R. Dispensatório farmacêutico - a botica do Hospital da Universidade. Subsídios para a sua História. In: COMISSÃO ORGANIZADORA DO CONGRESSO "HISTÓRIA DA UNIVERSIDADE", 7., 1991, Coimbra. Actas do Congresso História da Universidade. Coimbra: Universidade de Coimbra, 1991. p. 11-19.

PORTUGAL. Compêndio histórico do estado da Universidade de Coimbra no tempo da invasão dos denominados jesuítas e dos estragos feitos nas ciências e nos professores e directores que a regiam pelas maquinações e publicações dos novos Estatutos por eles fabricados. Lisboa: Régia Oficina Tipográfica, 1772.

\footnotetext{
Justino Pereira de Magalhães (Portugal, Lisboa) - Universidade de Lisboa (UL)

Pós-Doutor em Educação pela Ecole des Hautes Études en Sciences Sociales, University of Cambridge e L'Institut National de Recherche Pédagogique. Coordena o projeto Atlas-Reportório dos Municípios na Educação e na Cultura em Portugal (1820-1986).

Lattes: <http://lattes.cnpq.br/8663317745937201>.

E-mail: <justinomagalhaes@ie.ulisboa.pt>.
}

Recebido em 31 de dezembro de 2018. Aceito em 9 de janeiro de 2019.

Educação \& Formação, Fortaleza, v. 4, n. 10, p. 7-17, jan./abr. 2019

DOI: https://doi.org/10.25053/redufor.v4i10.865

http://seer.uece.br/redufor 